\title{
FROM FLIPPED, TO FLIPPING OUT, TO MOSTLY SUNNY: HOW THE FLIPPED CLASSROOM MODEL MADE THE MOVE TO EMERGENCY REMOTE LEARNING LESS STORMY
}

\author{
Meg Fryling, Siena College, mfryling@siena.edu
}

\begin{abstract}
In spring of 2020, COVID-19 forced traditional residential colleges to quickly move to emergency remote teaching (ERT). Even students and faculty with online and/or hybrid course familiarity likely experienced stress after the move to ERT as the courses were developed to be taught in-person and students expected face-to-face delivery. This study found that not only was some of the student stress related directly to concern about the COVID-19 virus and forced quarantine, but clarity of course expectations emerged as another possible factor. For faculty with in-person courses that had little to no asynchronous component, the move to ERT was likely most difficult as they were forced to completely rethink their pedagogical paradigm in a matter of days. This short timeframe gave faculty little time to adequate prepare and virtually no time to communicate the changes in course delivery to the students. The course in this study was redesigned as a flipped classroom in fall of 2019, with a substantial online asynchronous component, including lecture videos and regular communication via the learning management system (LMS). From a faculty perspective, the pre-developed asynchronous LMS modules made the migration to a fully remote learning environment fairly smooth and less time intensive than a traditional course with no asynchronous presence. Additionally, a vast majority of students perceived that the flipped classroom would make the move to ERT easier and liked the learning environment, even when the course was moved entirely remote. Migrating to a blended learning environment with a strong asynchronous presence, such as a flipped classroom model, is one way to not only enhance in-person course delivery but better prepare for future ERT scenarios.
\end{abstract}

Keywords: COVID-19, emergency remote teaching, flipped classroom, online education, synchronous online learning, distance learning, learning management systems, LMS

INTRODUCTION

\section{Emergency Remote Teaching}

In Spring of 2020, traditional residential higher education institutions were forced to rapidly move to Emergency Remote Teaching (ERT). Such a rushed and radical change caused considerable stress for faculty, administrators, and students. Zimmerman refers to this dramatic unexpected shift to remote learning as "The Great Online Learning Experiment" (2020). Some advocates for distance learning worry that this swift and massive move to remote learning may hurt the reputation of online education and they stress that ERT is not the same as a fully developed online course in many ways (Hodges, Moore, Lockee, Trust, \& Bond, 2020). First, students registered for a traditional in-person course. While they may have experience taking a fully online or hybrid course, they did not choose to do so for this particular course. Additionally, while faculty members thrown into ERT may have experience teaching online or hybrid courses, these particular courses were designed to be taught face-to-face. Finally, there was simply not adequate time to develop a proper online course, including working with instructional designers to design and implement learning materials that produce desired academic outcomes (Hodges et al., 2020; McMurtrie, 2020).

While the use of learning management systems (LMS) have become fairly common among higher education institutions ( $75 \%$ classes using), many classes have minimal content available for students (e.g. just a course syllabus). Additionally, only about $11.2 \%$ of classes use audio capture and $14.2 \%$ use lecture capture (Green, 2019). This lack of experience with tools that would typically be used for distance learning, makes the massive move of nearly all college institutions to ERT overwhelming for faculty, students, and IT departments. Faculty “....are trying to figure out the intricacies of their learning-management systems, unfamiliar conferencing technologies, and new 


\section{Issues in Information Systems \\ Volume 21, Issue 1, pp. 281-289, 2020}

protocols for coursework and tests, even as they reach out to students to find out where they are and what they need. And they are having to do it in a matter of days" (McMurtrie, 2020). According to a recent survey by the Chronicle of Higher Education, "about 60 percent of faculty members, and a similar share of academic administrators, said spring’s courses were worse than face-to-face offerings” (June, 2020).

Online education is simply different from in-person education and, as such, requires different pedagogical paradigms (Boyd, 2016; Harasim, 2000; Palloff \& Pratt, 2007). Additionally, while some courses may be well-matched for online delivery, some disciplines, such as CIS, often include hands-on activities that have close interaction with faculty and classmates, which may be better suited for in-person delivery (Kovacs, Peslak, Kovalchick, \& Wang, 2018). Kovacs, et al. (2018) found that over half of Computer Information Systems (CIS) students prefer in person course delivery versus online, “... with females and younger students expressing the most preference for the on-ground vs. online course delivery.”

\section{Flipped-Classroom}

While some students may believe that in-person course delivery is more effective than hybrid or fully-online (Kovacs et al., 2018), there is also research to suggest that the traditional lecture classroom has failed to help students master subject material (Clark, 2015; Gunyou, 2015; Vaughan, 2014). The flipped classroom model is a method of teaching that reserves classroom time for activities that are traditionally done outside of the classroom (e.g. homework assignments) and moves pure lecturing to outside of the classroom (e.g. via pre-recorded lectures) (Bishop \& Verleger, 2013; Clark, 2015; Gaughan, 2014; Herreid \& Schiller, 2013; Vaughan, 2014). This method of teaching is intended to increase student engagement and academic performance (Clark, 2015; Danker, 2015; Fryling, Yoder, \& Breimer, 2016; Gunyou, 2015; Strayer, 2012; Vaughan, 2014). Researchers have found that pre-recorded lecture videos are as effective as in-person (Zhang, Zhou, Briggs, \& Nunamaker, 2006) and that there are many positive outcomes of the flipped classroom model (Frydenberg, 2013; Fryling et al., 2016; Saulnier, 2015). As a result of their review and analysis of mixed instruction literature, Margulieux, et al. found that the flipped classroom model produced the highest increase in learning outcomes (2016). While residential colleges tend to focus on in-person teaching, a blended learning model with online components, such as a flipped classroom, is not only is a legitimate pedagogical enhancement to face-to-face activities but can also make the move to emergency remote teaching easier (Czerniewicz, Trotter, \& Haupt, 2019).

This research will explore the moods of student in an Introduction to Computer Science class during the transition from an in-person flipped classroom to emergency remote teaching and what impact the flipped-classroom model had on that transition to ERT.

\section{RESEARCH METHODOLOGY}

The institution in this study is a small liberal-arts college, which prides itself as being "...committed to a studentcentered education emphasizing dynamic faculty-student interaction.” The institution is primarily an undergraduate residential college, with 3103 undergraduate students, $72 \%$ of which live on-campus, and only 98 graduate students. As such, most of its courses are delivered in a traditional in-person environment with limited online and hybrid offerings. The course in this study has been taught by the instructor five times and is taken by both computer science majors (typically freshmen) and non-computer science majors (from all academic levels). In fall of 2019, the instructor changed the delivery of the course from traditional lecture environment to a flipped-classroom model in an effort to improve student experience. In spring of 2020, the course was taught for a second time in flipped format. This consisted of students watching 2-4 pre-recorded lecture videos each week, 2 hours of hand-on activities/worksheets off the computer (e.g. number conversion, writing code on paper) during the in-person lectures, and 2 hours of activities on the computer (e.g. programming, von Neumann simulation) during the in-person labs.

Once the course moved to fully remote, the students continued to watch the pre-recorded lecture videos and the normal lecture sessions were conducted synchronously via Canvas Conferences. Students were given activity worksheets to complete ahead of time while watching the lecture videos. During the live lectures (1 hour twice per week) the professor would work through the worksheets, soliciting answers from students. Attendance was similar to in-person, with at least $90 \%$ of the class attending each live session. While active class participation did drop once we moved to 


\section{Issues in Information Systems}

Volume 21, Issue 1, pp. 281-289, 2020

an online synchronous environment, on average 11 of the 31 students in the class would actively pose questions and/or provide answers to worksheet questions. These lecture sessions were recorded and made available via the Canvas LMS for students that missed the synchronous session, got disconnected, and/or for additional review before exams. The 2-hour lab sessions were also conducted synchronously and would begin with the professor introducing the lab for 15-20 minutes, followed by students working on their own. Students were asked to attend the introduction but were allowed to leave and work on their own after that. The professor would remain on the Canvas Conference for the entire 2 hours to answer questions, followed by virtual office hours during the week. The lab introductions were also recorded and made available on Canvas.

After the announcement that courses would move to $100 \%$ remote instruction after spring break, an initial pre-remote learning survey was given to all students in the class. A similar survey was then administered weekly (except for Easter break) for the remaining weeks (5 post-remote learning surveys in total).

Data from the student respondents were analyzed, focusing on the following survey questions:

- How are you feeling? ("Extra stormy”, "A little rainy”, "Mild”, "Partly sunny”, or "All sunshine”)

- What made you feel this way? (Open-ended question)

- How clear is your understanding of what is expected of you when taking your CSIS110 Introduction to Computer Science class remotely? (“Not clear”, "Slightly clear”, "Somewhat clear”, "Very clear”, "Extremely clear")

- How clear is your understanding of what is expected of you when taking your other (non-CSIS110) classes remotely? (“Not clear”, "Slightly clear”, "Somewhat clear”, "Very clear”, "Extremely clear”)

- The "flipped-classroom" format of CSIS110 Introduction to CS will make its move to fully-online easier. (“Strongly disagree”, “Disagree”, “Neither agree nor disagree”, “Agree”, “Strongly agree”)

This research centered upon the following research questions:

- What is the overall mood of the students prior to going remote?

- How did those moods change during the remainder of the semester?

- What are the reasons for those moods?

- Did the flipped-classroom model make the transition to emergency remote teaching smoother?

While the survey was originally developed to help prepare for the transition to ERT, provide support to students during ERT, and make any needed adjustments to the course during ERT, some themes emerged which are discussed in the results section below.

\section{RESULTS}

The survey responses varied from 24-30, with not all students completing every survey. Of the 30 original respondents, 17 (57\%) were male and 13 (43\%) were female. Only one of the thirty students were a computer science major, the rest were taking as an elective or business school auxiliary requirement. As for online learning experience, 12 (40\%) students had taken a fully online course before, 9 (30\%) had taken a hybrid course before, and 13 (43\%) had no prior online learning experience. Respondent moods once it was announced that courses were moving to a fully remote environment varied (see Figure 1), with 30\% being in the negative range (i.e. "A little rainy" and "Extra stormy"), $37 \%$ being in the positive range ("Partly sunny" and "All sunshine"), and 33\% being neutral ("mild"). 


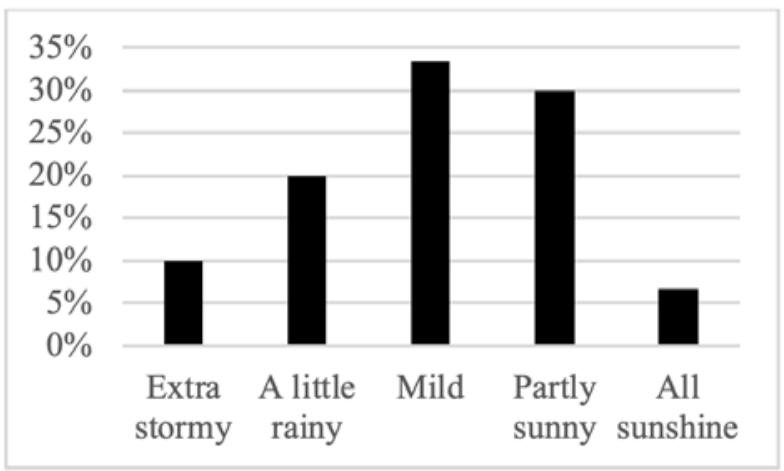

Figure 1. Student Moods Just After Announcement of Move to Remote Learning

After respondents were asked their current mood, they were then asked why they are feeling that way. This was an open-ended question. Figure 2 represents a word cloud of the most frequent words used. Both school related and coronavirus related words were frequently used terms. After coding the responses (see Figure 3), the primary themes that emerged for current state of mind also included social distancing/stay home (quarantine), missing the campus experience, and disappointment for missing the senior year experience (e.g. senior week, graduation).

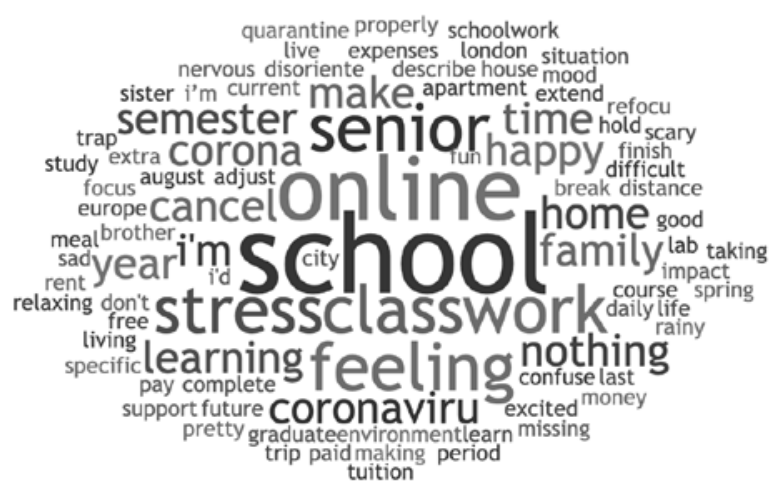

Figure 2. Reasons for Moods Just After Announcement of Move to Remote Learning

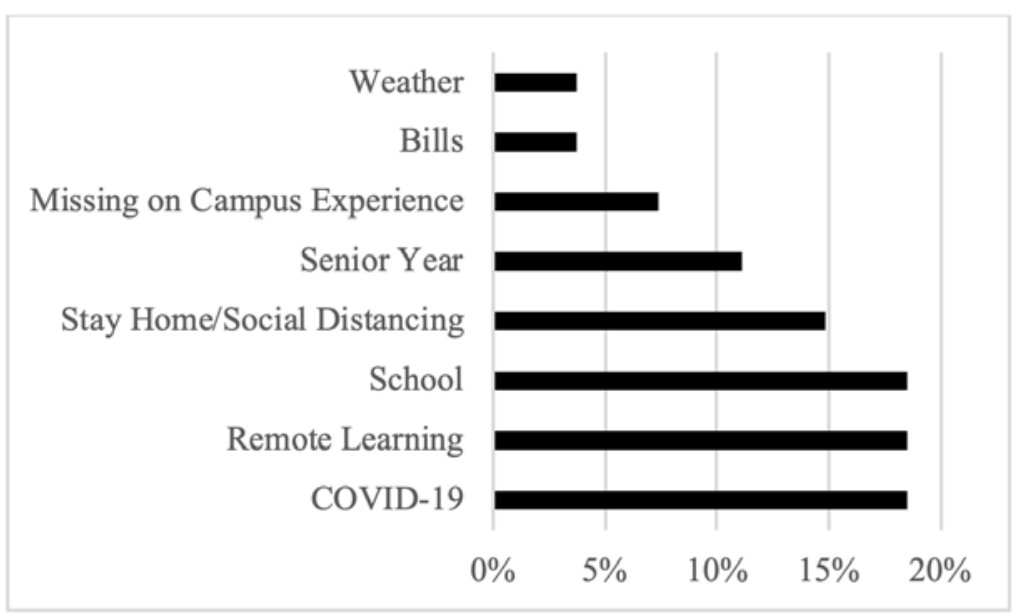

Figure 3. Coded Mood Reasons 
Somewhat surprisingly, student moods shifted immediately after remote learning began. The Post-Online 1 survey was administered at the beginning of the first week of remote learning. The negative moods (i.e. "Extra Stormy" and "A little rainy") had dropped from 30\% to $11 \%$ (see Figure 4). By the $3^{\text {rd }}$ Post-Online survey student moods had shifted even more in the positive direction with $62.5 \%$ reporting a positive mood ("All sunshine” and "Partly sunny"). However, there was a drop in positive moods the following week to $32 \%$, before rebounding to $61.5 \%$ the last week.

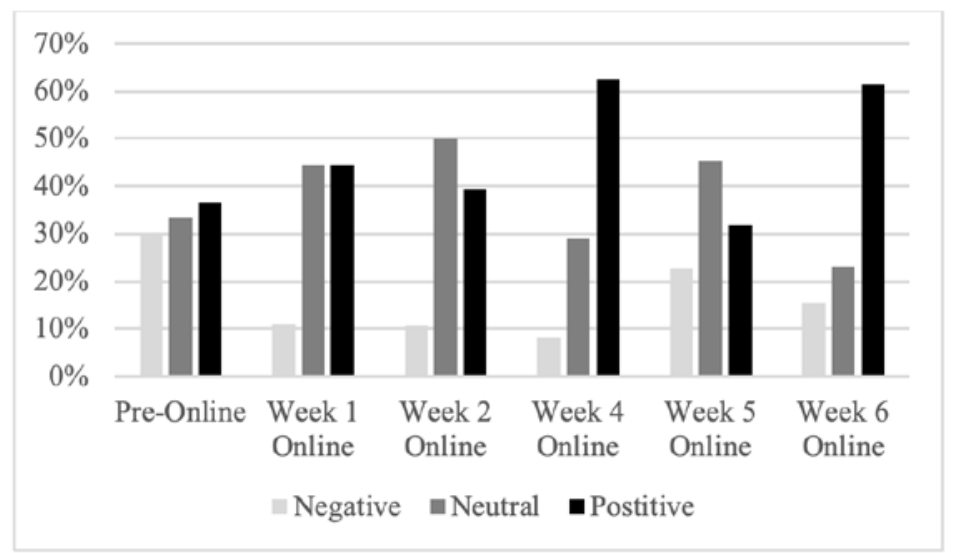

Figure 4. Moods Over Time

In addition to current mood and reasons for that mood, students were asked the following two questions in each of the surveys:

- How clear is your understanding of what is expected of you when taking your CSIS110 Introduction to Computer Science class remotely?

- How clear is your understanding of what is expected of you when taking your other (non-CSIS110) classes remotely?

Although the theme did not emerge from the "What made you feel this way?" open-ended question, an interesting pattern emerged between clarity of course expectations and overall mood. As shown in Figures 5 and 6, clarity of course expectations have a similar pattern to overall mood (Figure 4).

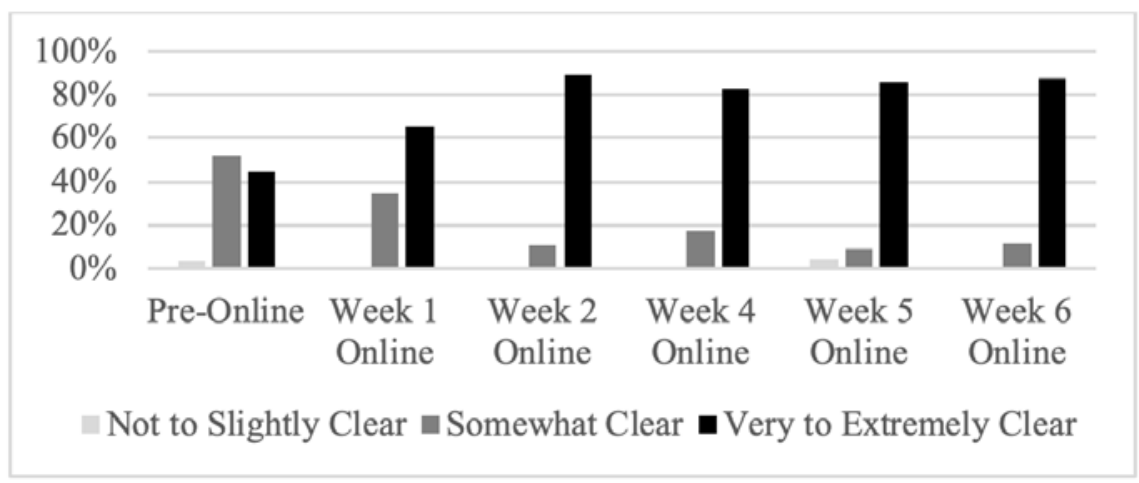

Figure 5. Clarity of Expectations for CSIS110 


\section{Issues in Information Systems}

Volume 21, Issue 1, pp. 281-289, 2020

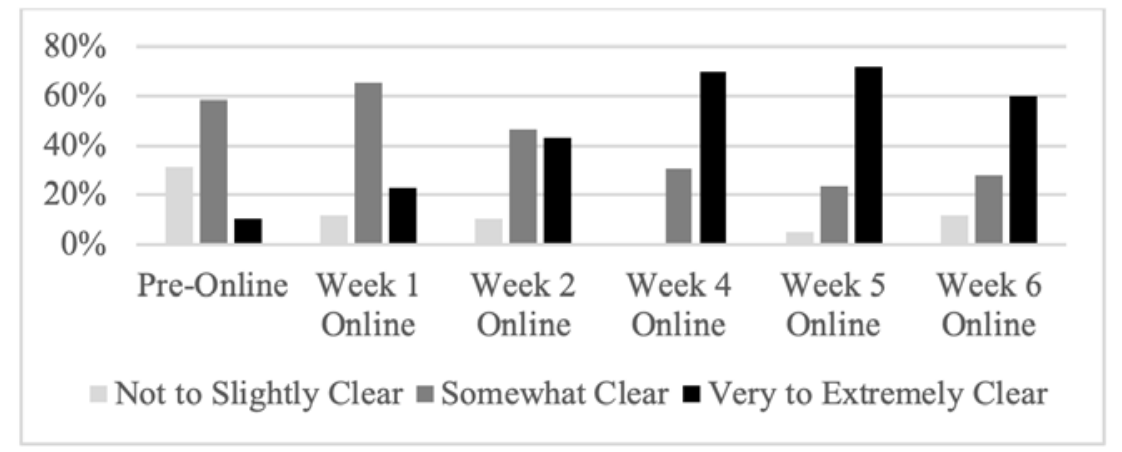

Figure 6. Clarity of Expectations for All Other Courses

Overall student respondents felt the expectations for their CSIS110 course were clearer than their other courses. While the exact reason for that is not known, it could be that the students were already familiar with the course's LMS components and accustomed to watching lecture videos outside of class. In the survey administered just prior to going to ERT, students were asked to what extent they agree that the "flipped-classroom" format of CSIS110 Introduction to CS will make its move to fully-online easier; a vast majority (80\%), agreed or strongly agreed (see Figure 7).

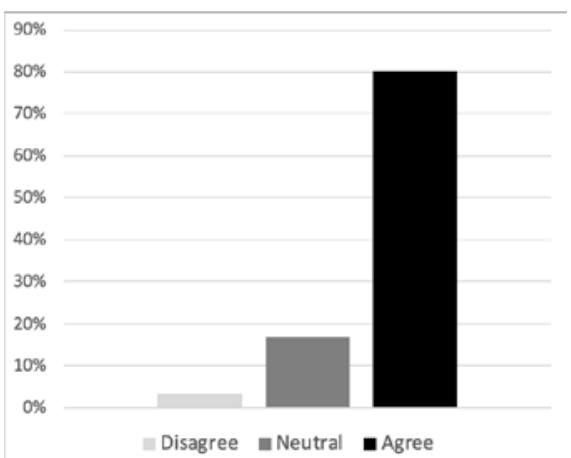

Figure 7. Flipped-Classroom Will Make Move to Fully-Online Easier

These data were collected in the pre-online survey so how did students feel about the flipped classroom at the end of the semester? On the regular course evaluations, always administered at the end of the semester, students were asked to what degree they agree that they "Liked the Flipped Classroom". Figure 8 shows that overall students liked the flipped format and students in the spring 2020 semester, when we had to move to ERT approximately halfway through the semester, actually liked the flipped classroom to a greater degree than the regular in-person semester (i.e. Fall 2019). 


\section{Issues in Information Systems}

Volume 21, Issue 1, pp. 281-289, 2020

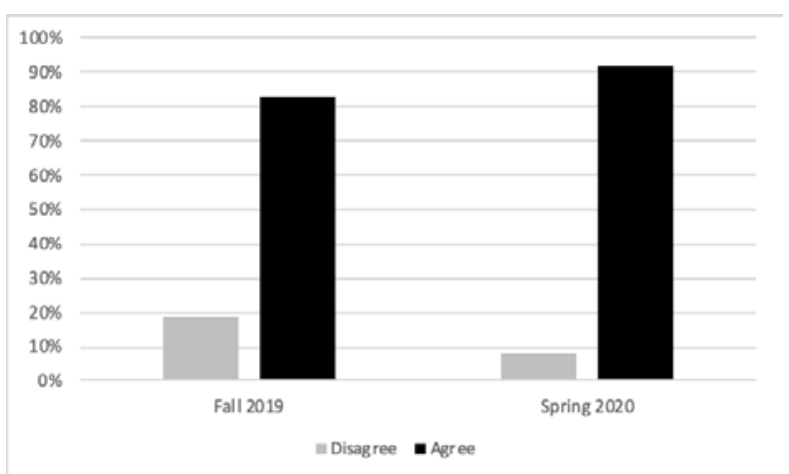

Figure 8. Percentage of Students that Liked Flipped-Classroom

As an exploratory study, there are clearly many limitations and continued research is warranted. Although students were asked the reason for their current mood, there may be unreported factors impacting mood. Additionally, the student's mood at it relates to ERT was impacted by all their courses. As such, we cannot say definitively that the flipped classroom format and clarity of course expectations were the cause of moods moving in a positive direction. Instead, this study provided some theories that require additional data collection and analysis.

\section{SUMMARY}

While not part of the original research questions, this study theorizes that giving students very clear expectations and maintaining frequent communication may be some ways to mitigate the stress of an unexpected move to emergency remote teaching (ERT). Even for traditional in-person courses, Learning Management Systems (LMS) can be used to communicate regularly to students, organize course content, and provide anytime access to course resources. Additionally, a blending learning environment, with a well-developed asynchronous online component (e.g. flipped classroom), can enhance traditional face-to-face classes and establish a framework for an unexpected move to fullyremote learning.

A vast majority of students perceived that the flipped classroom would make the move to ERT easier and liked the blending learning method. From a faculty perspective, the pre-developed asynchronous LMS modules made the migration to a fully remote learning environment fairly smooth and less time intensive than a traditional course with no asynchronous presence. As we prepare for the Fall 2020 semester, and beyond, developing more courses in a flipped format may not only improve the in-person experience but put faculty in a better position to move to ERT should a second COVID-19 wave occur and/or for future situations where leaving campus is warranted (e.g. another pandemic, extreme weather conditions, civil unrest).

\section{REFRENCES}

Bishop, J. L., \& Verleger, M. A. (2013, June 23-26). The Flipped Classrom: A Survey of the Research. Paper presented at the 120th ASEE Annual Conference \& Exposition, Atlanta, GA.

Boyd, D. (2016). What Would Paulo Freire Think Of Blackboard ${ }^{\mathrm{TM}}$ : Critical Pedagogy in an Age of Online Learning International Journal of Critical Pedagogy, 7(1), 165-186.

Clark, K. R. (2015). The Effects of the Flipped Model of Instruction on Student Engagement and Performance in the Secondary Mathematics Classroom. Journal of Education, 12(1), 91-115.

Czerniewicz, L., Trotter, H., \& Haupt, G. (2019). Online teaching in response to student protests and campus shutdowns: academics' perspectives. International Journal of Educational Technology in Higher Education, 16(43). 
Danker, B. (2015). Using Flipped Classroom Approach to Explore Deep Learning in Large Classrooms. IAFOR Journal of Education, 3(1), 171-186.

Frydenberg, M. (2013). Flipping Excel. Information Systems Education Journal, 11(1), 63-73.

Fryling, M., Yoder, R., \& Breimer, E. (2016). Full Flip, Half Flip and No Flip: Evaluation of Flipping an Introductory Programming Course. Information Systems Education Journal, 14(5), 4-16.

Gaughan, J. E. (2014). The Flipped Classroom in World History. The History Teacher, 47(2), 221-244.

Green, K. C. (2019). The 2019 Campus Computing Survey: The 30th National Survey of Computing and Information Technology in American Higher Education. Retrieved from https://static1.squarespace.com/static/5757372f8a65e295305044dc/t/5da60e02c69e0005bf93690e/1571163 656824/Campus+Computing+-+2019+Report.pdf

Gunyou, J. (2015). I Flipped My Classroom: One Teacher's Quest to Remain Relevant. Journal of Public Affairs Education, 21(1), 13-24.

Harasim, l. (2000). Shift happens: Online education as a new paradigm of learning. The Internet and Higher Education, 3(1), 41-61.

Herreid, C. F., \& Schiller, N. A. (2013). Case Studies and the Flipped Classroom. Journal of College Science Teaching, 42(5), 62-66.

Hodges, C., Moore, S., Lockee, B., Trust, T., \& Bond, A. (2020). The Difference Between Emergency Remote Teaching and Online Learning. Educause Review.

June, A. W. (2020). Did the Scramble to Remote Learning Work? Here’s What Higher Ed Thinks. The Chronicle of Higher Education.

Kovacs, P., Peslak, A., Kovalchick, L., \& Wang, W. (2018). Attitudes Toward Course Delivery: A Multi-University Study of Online, On-ground, And Hybrid Instruction. Information Systems Education Journal, 16(4), 27-33.

Margulieux, L. E., McCracken, W. M., \& Catrambone, R. (2016). A taxonomy to define courses that mix face-to-face and online learning. Educational Research Review, 19(November), 104-118.

McMurtrie, B. (2020). The Coronavirus Has Pushed Courses Online. Professors Are Trying Hard to Keep Up. The Chronicle of Higher Education, 66(26).

Palloff, R., \& Pratt, K. (2007). Building online learning communities: Effective strategies for the virtual classroom. San Francisco: Jossey-Bass.

Saulnier, B. (2015). The Flipped Classroom in Systems Analysis \& Design: Leveraging Technology to Increase Student Engagement. Information Systems Education Journal, 13(4), 33-40.

Strayer, J. F. (2012). How Learning in an Inverted Classroom Influences Cooperation, Innovation, and Task Orientation. Learning Environment Research, 15(2), 171-193.

Vaughan, M. (2014). Flipping the Learning: An Investigation into the use of the Flipped Classroom Model in an Introductory Teaching Course. Education Research and Perspectives, An International Journal, 41, 25-41.

Zhang, D., Zhou, L., Briggs, R. O., \& Nunamaker, J. F. (2006). Instructional video in e-learning: Assessing the impact of interactive video on learning effectiveness. Information \& Management, 43(1), 15-27. 


\section{Issues in Information Systems}

Volume 21, Issue 1, pp. 281-289, 2020

Zimmerman, J. (2020, March 10). Coronavirus and the Great Online-Learning Experiment. Chronicle of Higher Education. 